\title{
FENOTIPIA E CONCENTRAÇÃO INIBITÓRIA MÍNIMA (CIM) EM LINHAGENS DE ESCHERICHIA COLI ISOLADAS DE LEITÕES COM DIARRÉIA NAS FASES DE MATERNIDADE, CRECHE, CRESCIMENTO E TERMINAÇÃO
}

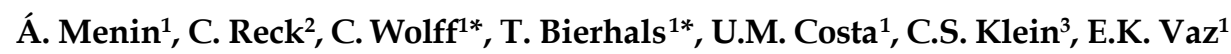

${ }^{1}$ Universidade do Estado de Santa Catarina, Centro de Ciências Agroveterinárias, Departamento de Medicina Veterinária, Laboratório de Imunologia e Doenças Infecto-Contagiosas, Av. Luis de Camões, 2090, CEP 88520000, Lages, SC, Brasil. E-mail: alvaromenin@yahoo.com.br

\section{RESUMO}

\begin{abstract}
Escherichia coli é reconhecida como causa freqüente de diarréia em suínos em todo o mundo. O objetivo do presente estudo foi caracterizar fenotipicamente os tipos fimbriais de 349 linhagens de E. coli isoladas de suínos com diarréia, em diferentes faixas etárias, utilizando os testes de microhemaglutinação e soroaglutinação, bem como determinar o perfil de suscetibilidade frente aos principais antimicrobianos utilizados em granjas de suínos. Do total de 159 linhagens de $E$. coli que não aglutinaram eritrócitos no teste de hemaglutinação manose-resistente (HAMR), 57 (35\%) foram positivas para a expressão do antígeno fimbrial F6 no teste de soroaglutinação rápida em placa. Considerando a faixa etária e o fenótipo fimbrial, os sorotipos de E. coli, potencialmente patogênicos mais prevalentes até a terceira semana de idade, foram F5 (K99), F6 (987P), F42 e F41 em, respectivamente, $29 \%, 23 \%, 11 \%$ e $10 \%$ das linhagens. Em leitões com mais de 25 dias, predominaram fimbrias F4 (K88) em 44,6\% (58) das linhagens. Os animais foram suscetíveis às cepas contendo F4, durante todas as faixas etárias, mas com maior predominância em idades mais avançadas, acima de 76 dias. Os maiores índices de resistência das linhagens foram observados para oxitetraciclina $(84,0 \%)$, gentamicina $(76,0 \%)$ e amoxicilina $(72,0 \%)$. Os menores valores de Concentração Inibitória Mínima (CIM) 50 e 90 foram observados para o ceftiofur.
\end{abstract}

PALAVRAS-CHAVE: Escherichia coli, suínos, fimbrias, CIM, resistência aos antimicrobianos.

\section{ABSTRACT}

PHENOTYPIC CHARACTERIZATION AND MINIMAL INHIBITORY CONCENTRATIONOF STRAINS OF ESCHERICHIA COLI ISOLATED FROM PIGS WITH DIARRHEA IN NEWBORN PIGLETS, POSTWEANING, GROWING AND FINISHING. Escherichia coli is recognized as a frequent cause of diarrhea in swine. The objective of this study was to phenotypically characterize the fimbrial types of 349 E. coli strains isolated from swine with diarrhea, in different age groups, through the microhemagglutination and seroagglutination tests and to determine the susceptibility profile in regard to the more common antimicrobials used on pig farms. Of the 159 strains that not agglutinate eritrocytes in the manose-resistant hemagglutination test (HAMR), 57 (35\%) were positive for the expression of the fimbrial antigen $\mathrm{F} 6$, in the fast seroagglutination test carried out in plates. Considering the age group and the fimbrial phenotype, the potentially pathogenic serotypes of E. coli more prevalent until the third week of age were: F5 (K99), F6 (987P), F42 and F41 in, respectively, $29 \%, 23 \%, 11 \%$ and $10 \%$ of the strains. In piglets over 21 days old, fimbriae F4 (K88) predominated in $44.6 \%$ (58) of the strains. The animals were susceptible to strains containing F4, in all of the age groups, but with more frequency at more advanced ages, above 76 days. The largest resistance indexes were observed for oxytetracycline $(84.0 \%)$, gentamicin (76.0\%) and amoxicilin (72.0\%). The smallest CIM 50 and 90 values were observed for ceftiofur.

KEY WORDS: Escherichia coli, swine, fimbriae, CIM, multiple drug resistance.

\footnotetext{
${ }^{2}$ Instituto Catarinense de Sanidade Animal, Concórdia, SC, Brasil.

${ }^{3}$ EMBRAPA - Suínos e Aves, Concórdia, SC, Brasil.

*Bolsista CNPq - CAV/UDESC.
} 


\section{INTRODUÇÃO}

A colibacilose é uma das doenças mais importantes para a exploração de carne suína em todo o mundo, considerada a maior causa de perdas econômicas e de produção, decorrente da alta morbidade e mortalidade em diferentes faixas etárias (ROMERo et al., 1998; HANSEN, 2006).

O potencial patogênico e a participação de Escherichia coli (E. coli) na patogênese das infecções entéricas em suínos estão intimamente associados a capacidade das linhagens de expressarem diferentes fatores de virulência, incluindo fatores de colonização (fimbrias) e a produção deenterotoxinas (MARTINS et al., 2000; Francis, 2002b; Grles et al., 2004). Os antígenos fimbriais possibilitam a adesão/fixação da bactéria na mucosa intestinal, mediante a ligação específica a receptores, situados nos enterócitos do epitélio intestinal dos suínos, permitindo a ação das enterotoxinas que, ligadas a receptores específicos dos enterócitos, ativam os sistemas guanil cilase e/ou adenil ciclase, aumentam a concentração intracelular de AMP cíclico e levam a um quadro de diarréia secretória (NATARO; KAPER, 1998; BerTSChinger, 1999; GYLES et al., 2004).

As fímbrias são apêndices filamentosos com 2-7 nanômetros de comprimento presentes na superfície celular (Holland, 1990). Cada fímbria écomposta por centenas de subunidades polipeptídicas repetidas que conferem estrutura, especificidade antigênica e a propriedade de ligação/adesão específicas a determinados sítios presentes nas células intestinais (GYLES et al., 2004).

E. coli é capaz de sintetizar vários tipos fimbriais que possibilitam a colonização do trato intestinal de diversas espécies animais. Em suínos, as fimbrias comumente relacionadas com distúrbios entéricos são F4 (K88 ab, ac, ad $\left._{1}\right)$, F5 (K99), F6 (987P), F41, F42, e F18 ab, ac (FAIRBROTHERet al., 1986; FrANCIS, 2002a). Entretanto, a expressão in vitro de determinados tipos fimbriais sofre a influência do meio de cultivo e também do $\mathrm{pH}$, osmolaridade, tensão de oxigênio e temperatura de cultivo (Holland, 1990).

Considerando a característica hemaglutinante, as fímbrias de $E$. coli podem ser classificadas em três grupos: fímbrias não hemaglutinantes como exemplo a fímbria F6; fímbrias tipo 1 (F1) ou manose-sensíveis (HAMS) que têm a sua aglutinação com eritrócitos inibida pela manose; e fímbrias manose-resistentes (HAMR) que não apresentam hemaglutinação inibida pela manose (SNYDER;KOCH, 1966; EvANS et al.,1979; GaAstra; GraAf, 1982; Morris, 1983). As fímbrias HAMR compreendem um grupo heterogêneo de estruturas da superfície bacteriana que se liga a carboidratos, exceto a manose, presentes nos receptores dos eritrócitos de diferentes espécies animais
(Wilson; Hohmann, 1974; Evans et al., 1979; GaAstra; GRAAF, 1982; MORRIS, 1983; QuADRI et al., 1994).

Além das propriedades de adesão, linhagens de E. coli podem produzir outros fatores de virulência importantes na patogenia das enfermidades, como a hemolisina. Esta característica é, com freqüência, considerada por alguns autores como um marcador de virulência e indicador de patogenicidade para linhagens de E. coli (Ludwig; Goebel, 1997; Van Den Bosch et al., 1982).

Odiagnóstico definitivo da colibaciloseem suínos deve considerar as características clínicas, anatomopatológicas, isolamento microbiológico e, principalmente, a caracterização fenotípica e/ou genotípica dos isolados, visto que a maioria das linhagens de $E$. coli presentes no trato gastrintestinal é comensal (BERTSCHINGER, 1999; HOLLAND, 1990).

Atualmente, diversos são os recursos utilizados para diagnosticar e biotipificar os fatores de patogenicidade de E. coli. Para avaliar a expressão fenotípica dos tipos fimbriais, os testes mais freqüentemente utilizados são hidrofobicidade, adesão celular, microhemaglutinação, ensaio imunoenzimático (ELISA), imunofluorescência indireta (IFA) e sorodiagnóstico. Para genotipificação tem sido utilizado o teste da reação em cadeia da polimerase (PCR) (FRANCIS, 2002b; GUEDES, 2006a). O uso continuado de antimicrobianos na criação de suínos em diferentes fases da produção para o tratamento de infecções bacterianas, especialmente entéricas, pode acarretar o aumento da pressão seletiva para linhagens bacterianas multi - resistentes aos antimicrobianos.

Osobjetivos do presente estudo foram caracterizar fenotipicamente os tipos fimbriais de linhagens de $E$. coli isoladas de leitões com diarréia utilizando a microhemaglutinação, sorodiagnóstico, bem como determinar o perfil de suscetibilidade dos isolados aos principais antimicrobianos utilizados em suinocultura.

\section{MATERIAL E MÉTODOS}

Seleção e amostragem do rebanho: as 349 linhagens de E.coli estudadas foram isoladas deleitões que apresentavam sinais clínicos de diarréia, sendo amostrados 219 leitões da fase de maternidade, $94 \mathrm{da}$ fase de creche e 36 da fase de terminação. Foram amostradas 176 granjas localizadas em 11 microrregiões geográficas do Estado de Santa Catarina. A obtenção do material para análise laboratorial foi realizada a partir da eutanásia, necropsia e coleta de material entérico de leitões das fases de maternidade, creche e terminação. Foram coletadas amostras de porções intestinais, priorizando intestino delgado e grosso. O material coletado foi acondicionado sob 
refrigeração para exame bacteriológico. Por ocasião da necropsia foi feito registro do material, descrevendo histórico, identificando o animal, sua procedência, sinais clínicos, suspeita clinica e lesões macroscópicas.

Cultivo microbiológico: o isolamento de E. coli foi foi baseado na semeadura do material coletado em meios de cultura enriquecido Ágar Sangue (com 5\% de sangue ovino desfibrinado) (AS) ${ }^{a}$, e Agar MacConkey $(\mathrm{MC})^{a}$. Após a semeadura, os meios de cultura foram incubados em estufa bacteriológica sob condições de temperatura de $37^{\circ} \mathrm{C}$ e $85 \%$ umidade relativa do ar. $\mathrm{O}$ crescimento bacteriano era avaliado em 24 e 48 horas decultivo. A identificação bacteriana foi baseada na análise de morfologia das colônias e/ ou de crescimento bacteriano, presença, ausência e padrão de hemólise, características morfotintoriais e caracterização fenotípica da bactéria através de testes bioquímicos segundo QuinN etal. (1994). Uma colônia típica isolada das culturas positivas foi repicada para AS com vistas.

Caracterização fenotípica: a fenotipificação das linhagens de E. coli foi realizada na EMBRAPA Suínos e Aves, Concórdia, SC. As fímbrias foram pesquisadas utilizando a técnica de microhemaglutinação (HA), com suspensões a 1\% de hemácias de cobaio, galinha, ovino e eqüino em presença de D-manose $1 \%$. As suspensões de hemácias foram obtidas de sangue fresco, após coleta em solução anticoagulante de Alsever e lavagens sucessivas com solução de PBS, pH7,4. As colônias bacterianas foram cultivadas em meio Minca a $37^{\circ} \mathrm{C}$, durante 24 horas. O teste foi realizado em microplaca de base em "U". Foram realizadas diluições em solução salina tamponada (PBS - Phosphate buffer solution) a partir de 1:2 até 1:128, em volumes de $50 \mu \mathrm{L}$, da suspensão bacteriana padronizada a uma leitura no espectrofotômetro de 2 D.O. a 675 nm e $50 \mu \mathrm{L}$ da suspensão de eritrócitos a $1 \%$. A leitura e interpretação foram realizadas após 12 horas de incubação a $4^{\circ} \mathrm{C}$ (Jones; Rutter, 1974; AwAd-Masalmeh et al., 1982).

Teste de suscetibilidade aos antimicrobianos:as linhagens de E. coli foram submetidas ao teste da concentração inibitória mínima (CIM) segundo National Committee for Clinical Laboratory STANDARDS, 2003). As linhagens de E. coliforaminoculadas em caldo Muller Hinton ${ }^{\mathrm{a}}$ e incubadas a $37^{\circ} \mathrm{C}$ por 3 horas. Em seguida, a cultura foi diluída em solução salina até atingir nível de turbidez equivalente a 0,5 da escala de McFarland ou uma concentração de aproximadamente $10^{6} \mathrm{UFC} / \mathrm{mL}$ de caldo. Em cada poço da microplaca foram depositadas alíquotas de $50 \mu \mathrm{L}$ da cultura. Um volumeigual, do antimicrobiano, foi adicionado no primeiro poço de cada linha e, a partir deste, diluído na razão $1: 2$ até 1:512. As microplacas foram incubadas a $37^{\circ} \mathrm{C}$ por 18 horas e em seguida procedeu-se a leitura (NCCLS, 2003).

Produção dos soros hiperimunes monoespecíficos: a produção de soros e análise sorológica dos isolados de E. coli foi realizada na EMBRAPA - Suínos e Aves, Concórdia, SC. Os soros hiperimunes monoespecíficos anti-fímbrias F5 e F6 foram produzidos a partir de linhagens de E. coli que expressavam as respectivas fímbrias na superfície bacteriana. Os isolados foram cultivados em meio Minca a $37^{\circ} \mathrm{C}$ durante $24 \mathrm{~h}$ e as células baterianas foram ressuspendidas em tampão fosfato (PBS) com $0,4 \%$ de formalina, incubadas por 6 horas a $37^{\circ} \mathrm{C} \mathrm{e}$, posteriormente, 18 horas a $4^{\circ} \mathrm{C}$, e padronizadas para um inóculo de $2 \times 10^{9}$ células $/ \mathrm{mL}$. Coelhos albinos, machos adultos, foram inoculados no dia zero com 0,5 mL do inóculo (suspensão bacteriana) inativado com formol, via subcutânea, previamente padronizado e, posteriormente, em intervalos de quatro dias, procedia-se a inoculação dos volumes de $0,5 \mathrm{~mL}$ (suspensão bacteriana inativada com formol via subcutânea); 0,5 mL (suspensão bacteriana inativada com formol) intravenosa, em seguida foram realizadas mais quatro inoculações de 1,0; 2,0; 3,0 e 3,0 mL (suspensão bacteriana viva, IV). No sétimo dia após a última inoculação, os animais foram eutanasiados, o sangue coletado, o soro separado e aliquotados, adicionados de $25 \%$ de glicerol e conservados a $-20^{\circ} \mathrm{C}$. Posteriormente, o soro foi adsorvido com a respectiva cepa bacteriana, cultivada a $18^{\circ} \mathrm{C}$ durante quatro dias em meio Triple sugar iron (TSA) ${ }^{a}$, para remover os anticorpos anti-antígenos $\mathrm{Ke} \mathrm{O}$.

Determinação dos antígenos fimbriais: foi realizada por soroaglutinação rápida em lâmina (SARP). Para realizar o teste as linhagens de E. coli foram cultivadas em meio Minca ${ }^{\mathrm{a}}$ a $37^{\circ} \mathrm{C}$ durante $24 \mathrm{~h}$. Em uma placa foram adicionados $30 \mu \mathrm{L}$ de anti-soro monoespecífico e igual quantidade de suspensão bacteriana padronizada para 7,0 da escala MacFarland. A leitura foi procedida após um minuto de homogeneização (JoNEs, 1974).

Detecção de atividade hemolítica: a atividade hemolítica foi avaliada utilizando ágar sangue contendo $5 \%$ de sangue de ovino desfibrinado, seguida de incubação por 24 horas a $37^{\circ} \mathrm{C} 24$ horas. As linhagens que apresentaram halo de hemólise total ou parcial ao redor das colônias foram consideradas hemoliticas (LUDWIG, 1997).

Estoque das linhagens deE. coli:as linhagens após identificadas e caracterizadas foram mantidas estocadas em Dorset Egg Medium ${ }^{\mathrm{b}}$ à temperatura de $4^{\mathrm{o}} \mathrm{C}$.

\footnotetext{
aSigma - Aldrich - Brasil.

bBiobrás - Brasil.
} 


\section{RESULTADOS E DISCUSSÃO}

Os resultados de microhemaglutinação em presença de manose (HAMR) estão apresentados na Tabela 1.

Das 349 linhagens de E. coli isoladas, 159 (45,7\%) não apresentaram atividade hemaglutinante no teste HA resistente à manose. Os dados encontrados são semelhantes aos resultados descritos por outros autores que, estudando fatores de virulência avaliando fenótipo fimbrial de isolados de E. coli obtidos de leitões com diarréia, observaram que, aproximadamente, $49 \%$ das linhagens de $E$. coli não apresentaram hemaglutinação na presença de manose (BRito et al., 2003; KLein et al., 2003).

No presente estudo, em 159 linhagens não hemaglutinantes, 57 (36\%) foram positivas para o fenótipo fimbrial $\mathrm{F} 6$ no teste de soroaglutinação rápida em placa (SARP). Estas observações reforçam que os resultados negativos no teste de HA devem ser interpretados com cautela, pois esse perfil, no teste de HA, pode indicar a presença de diferentes biotipos fimbriais, ou ainda a possibilidade de novos fatores de adesão, ainda sem caracterização hemaglutinante. Neste contexto faz-se necessário a utilização de um teste diferencial como aglutinação em látex, sorologia monoespecífica ou teste de ELISA para caracterização fenotípica diferencial das linhagens F6 positivas. Ademais, éimportante considerar a participação cada vez mais freqüente e significativa dos biótipos F6 e F1 na patogênese das diarréias em leitões até os 21 dias de idade e a relação entre a expressão dos diferentes fatores de virulência (Jones; RutTer, 1974; Holland, 1990; MARTINs et al., 2000).

Avaliando fatores de virulência de linhagens de $E$. coli, outros estudos relataram que há uma intima relação entre o potencial de expressão de adesinas fimbriaiseacapacidadedeexpressãodeenterotoxinas, assim como a produção de toxinas sem apresentar o antígeno fimbrial que, neste caso, é explicado pela perda do plasmídeo que codifica o fator de adesão durante os procedimentos laboratoriais (ОАЕK, 1999; MARTINs et al., 2000; POST et al., 2000).

Dos 349 isolados de E. coli, 190 (54,3\%) linhagens expressaram um perfil determinado de hemaglutinação para os eritrócitos de diferentes espécies no teste deHA em presença de D-manose. Estes dados diferiram pouco dos resultados descritos por outros autores que observaram $62,1 \%$ de freqüência de atividade HAMR às hemácias de ovino, cobaia, eqüino e galinha, estudando linhagens virulentas de E. coli isoladas de leitões com diarréia de diferentes faixas etárias (BRiTo et al., 2003).

Considerando a faixa etária e o fenótipo fimbrial encontrado nos 349 isolados (Tabela 1), foi observado que os sorotipos fimbriais mais prevalentes na faixa etária até 21 dias foram F5, F6, F42 e F41. Em idades a partir dos 25 dias, houve uma maior ocorrência de linhagens portadoras do tipo fimbrial F4. Dados semelhantes foram demonstrados em estudos similares realizados nos EUA, investigando a prevalência de fatores de virulência de $E$. coli entéricas em suínos (Post et al., 2000; Francis, 2002a).

A ocorrência dos fenótipos fimbriais observada no presente estudo caracteriza efetivamente certa predisposição dos leitões em determinadas faixas etárias a tipos fimbriais específicos. Esta observaçãoéconfirmada por outros autores que, estudando a incidência e virulência de $E$. coli em suínos, descrevem padrões desusceptibilidade aos diferentes grupos antigênicos de E. coli patogênicas associadas à idade, determinados por fatores como a variabilidade na condição de expressão e disponibilidade de receptores na membrana plasmática dos enterócitos (AWAD-MASALMEHet al., 1982; FRANCIS, 2002a).

Tabela 1 - Distribuição e freqüência dos fenótipos fimbrias de 349 linhagens de E. coli, isoladas de leitões com diarréias em diferentes faixas etárias, diagnosticados pelo teste de microhemoaglutinação manose-resistente e soroaglutinação rápida em placa, Concórdia, SC, 2006.

\begin{tabular}{|c|c|c|c|c|c|}
\hline \multirow[t]{2}{*}{ Antígeno fimbrial } & \multirow[t]{2}{*}{ Distribuição e freqüência (\%) } & \multirow{2}{*}{$\frac{\text { Hemólise }}{(+)^{1}}$} & \multicolumn{3}{|c|}{ Distribuição e freqüência (\%) por faixa etária } \\
\hline & & & $0-25$ dias & 26-75 dias & $>76$ dias \\
\hline HAMR Positivas & $190(54,3)$ & 32 & $123(56,2)$ & $48(51,1)$ & $19(52,8)$ \\
\hline HAMR Negativas & $159(45,7)$ & 72 & $96(43,8)$ & $46(48,9)$ & $17(47,2)$ \\
\hline $\mathrm{F} 4(\mathrm{~K} 88)$ & $66(19,0)$ & 63 & $9(4,1)$ & $39(41)$ & $19(52)$ \\
\hline F5 (K99) & $73(20,8)$ & 0 & $70(32)$ & $2(2,6)$ & 0 \\
\hline F6 (987P) & $57(16,3)$ & 8 & $57(26)$ & 0 & 0 \\
\hline F41 & $24(6,8)$ & 0 & $20(9)$ & $4(4,3)$ & 0 \\
\hline F42 & $27(7,7)$ & 1 & $24(11)$ & $3(3,1)$ & 0 \\
\hline SAFD $^{2}$ & $102(29)$ & 32 & $39(17,9)$ & $46(49)$ & $17(48)$ \\
\hline
\end{tabular}

${ }^{1}$ Atividade hemolítica positiva; ${ }^{2}$ Sem antígeno fimbrial definido. 
Tabela 2 - Valores de Concentração Inibitória Mínima (CIM) capazes de inibir 50\% e 90\% (CIM50 e CIM90) de 349 linhagens de E. coli e freqüência (\%) de resistência dos isolados a diferentes antimicrobianos. Concordia, SC, 2006.

\begin{tabular}{lcccc}
\hline Antimicrobiano & Concentração $(\mu / \mathrm{mL})$ & CIM 50 & CIM 90 & Freqüência de resistência $(\%)$ \\
\hline Amoxicilina & $0,25-128$ & $>32$ & $>32$ & 72 \\
Ceftiofur & $0,25-128$ & 0,25 & 1 & 37 \\
Colistina & $0,008-32$ & 2 & 4 & 69 \\
Doxicilina & $0,25-128$ & 8 & $>16$ & 67 \\
Enrofloxacina & $0,008-32$ & 0,5 & $>32$ & 39 \\
Gentamicina & $0,25-128$ & 16 & $>128$ & 76 \\
Neomicina & $0,25-128$ & 32 & $>128$ & 66 \\
Norfloxacina & $0,008-32$ & $>32$ & $>32$ & 63 \\
Oxitetraciclina & $0,25-128$ & $>128$ & $>128$ & 84 \\
\hline
\end{tabular}

${ }^{a}$ CIM necessária para inibir o crescimento de $50 \%$ das amostras testadas.

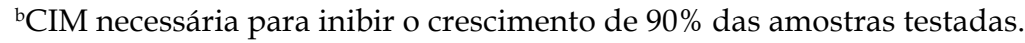

Foi observada nas linhagens que expressaram o antígeno F4 a ocorrência em leitões de todas as faixas etárias estudadas, com maior freqüência a partir dos 26 dias de idade chegando a estar associado a quadros de colibacilose em animais com mais de 76 dias.

A ocorrência de fenótipos fimbrias $\mathrm{F} 4$ em diversas fases de criação de suínos (Tabela 1) corrobora com afirmações de outros autores que citam que as linhagens com este fenótipo fimbrial pode acometer animais de 0-8 semanas de idade, mas com maior freqüência a partir da terceira semana, tendo menor importância patogênica a partir dos 60 dias de idade. A suscetibilidade a este fenótipo está associada a característica autossômica que determina a expressão de componentes que atuam como receptores fimbriais no intestino dos leitões. Em contraste, o estado de resistência se dá devido aos receptores serem bloqueados por compostos presentes no conteúdo intestinal (glicocálice), mudança de alimentação ou estabelecimento de defesas imunitárias passivas e ativas (Holland, 1990; NATARO; KAPER, 1998; OsEK, 1999; FrANCIS, 2002a).

Entretanto, a associação de $E$. coli $\mathrm{F} 4$ com quadros de diarréia em animais com mais de 80 dias possivelmente encontra justificativa na interação dos isolados potencialmente patogênicos, com outros fatores infecciosos (vírus, bactérias, fungos), ou não infecciosos (superlotação e manejo inadequado) que geram quadros imunossupressivos.

E. coli F5, F6, F41 e F42 ocorreram com grande freqüência em animais até a terceira semana de vida. Dados semelhantes foram descritos por outros autores que, estudando fatores de virulência emE. coli isoladas de animais com diarréia, encontraram relação etária similar para os referidos biotipos fimbriais (FAIRBROTHER et al., 1986; Guedes et al., 2006b). Além disso, outros autores descrevem E. coli F5, F6 e F41 são idade-restritas, pois só acometem leitões até a segunda semana de vida. Esta predisposição etária encontra reflexo na diminuição da concentração dos receptores para F5 com o crescimento dos animais, enquanto os receptores para F6, F41 e F42 são bloqueados por ligantes análogos presentes no lúmen intestinal (FRANCIS, 2002a).

Das 349 linhagens de E. coli, 104 (29,7\%) foram positivas para produção dehemólise. Destas, 19(8,6\%) foram isoladas de leitões com até 21 dias de idade e 85 $(65,4 \%)$ de leitões com idade acima de 21 dias. Resultados semelhantes foram descritos por outros autores que, avaliando este fenótipo em E. coli isoladas de leitões com diarréia, descreveram $26,4 \%$ de positividade para a produção de hemolisinas, das quais $6,5 \%$ em isolados provenientes de leitões lactentes e $52 \%$ em amostras de leitões desmamados (MARTINs et al., 2000; BRITo et al., 2003).

Estes dados reforçam que esta característica fenotípica não deve ser utilizada como único critério para classificar estirpes patogênicas de $E$. coli, que causam diarréia em leitões lactentes, em virtude da baixa ocorrência deste fenótipo nesta faixa etária. Entretanto, a presença de hemolisina é bom indicador de virulência em estirpes isoladas de animais acima de 21 dias de idadeoudesmamados. Estes dadosconcordamcomos achados de outros autores que associaram a produção de hemolisinas com maior freqüência aos patotipos fimbriaisF4eF18, predominantesapósaterceirasemana devida, em detrimento dos biotiposF5,F6, F41 eF42que ocorrem mais na fase lactente do leitão (MARTins etal., 2000; FRANCIS, 2002b; BRITOet al., 2003).

Das 349 linhagens de E. coli isoladas de animais com diarréia somente $246(70,6 \%)$ revelaram fenótipo patogênico utilizando o teste deHA e sorodiagnóstico. A discrepância entre os resultados de estudos fenotipicos e genotipicos podem decorrer de que certas linhagens bacterianas podem não expressar o fenótipo em condições in vitro ou vir a perder a característica genética (plasmídio) durante os procedimen- 
tosdecultivo. Releva-senotartambémoriscodemensurar a presença dos genes não-funcionais nos quais ofator de virulência não é expresso (AwAD-MASALMEHet al., 1982; FRANCIS, 2002a). Comêxito, para odiagnóstico definitivo das diarréias, outras causas infecciosas (vírus, protozoários e bactérias) ou não infecciosas (intoxicações, ambiente, manejo) devem ser pesquisadas, abordando os distúrbios entéricos sob a forma de síndrome.

As linhagens de E. coli revelaram elevado índice de resistência aos diferentes antimicrobianos utilizados (Tabela 2), disponíveis comercialmente para afecções em suínos. Nesteestudo, as maiores taxas de resistência foram observadas para oxitetraciclina $(84,0 \%)$ e gentamicina $(76,0 \%)$ emenores taxas deresistência para ceftiofur $(37,0 \%)$ eenrofloxacina $(39,0 \%)$. Outrosautores que, estudando a resistência antimicrobiana em $E$. coli isoladas de leitões com diarréia, verificaram valores de resistência inferiores para enrofloxacina (24\%) e gentamicina (38\%) e valores de resistência mais elevados para oxitetraciclina (100\%) (HABRUM et al., 2004).

As diferenças observadas entre os resultados dos estudos a podem ser atribuídas aos diferentes protocolos terapêuticos (dosagem, tempo de terapia) utilizados nos programas sanitários que poderiam influenciar diretamente na pressão de seleção de populações bacterianas.

Para CIM50 e CIM90 (Tabela 2) foram encontrados valores superiores aos relatados por BACARRO et al.(2002) que, ao determinar em CIM50 e90 em linhagens de E.coli isoladas de leitões com diarréia provenientes do Estado deSãoPaulo, verificaramuma maior CIM50 $(1,0 \mu \mathrm{g} / \mathrm{mL})$ e CIM90 $(2,0 \mu \mathrm{g} / \mathrm{mL})$ para ceftiofur. Em contraste, no presenteestudoparaamesmadrogaforamencontrados valores de 0,25 e 1,0 $\mu \mathrm{g} / \mathrm{mL}$ para CIM50 e CIM90. Esta diferença possivelmentesedeve porquea drogaédeuso relativamente recente e não induz de forma expressiva a seleção de linhagens E. coli resistentes.

\section{CONCLUSÃO}

A fenotipificação das fimbriais e determinação do perfil de resistência aos antimicrobianos dos isolados de E. coli são fundamentais no estudo da virulência das linhagens, fornecendo subsídios aos estudos de epidemiologia e na instituição de protocolos terapêuticos para o tratamento da colibacilose em suínos em diferentes faixas etárias.

\section{AGRADECIMENTOS}

Os autores agradecem ao Centro de Ciências Agroveterinárias (CAV) da Universidade do Estado de Santa Catarina (UDESC), à Empresa Brasileira de Pesquisa Agropecuária (EMBRAPA - Suínos e Aves) pela disponibilidade dos laboratórios e apoio a pesquisa e ao Conselho Nacional de Desenvolvimento Científico e Tecnológico (CNPq) pelo financiamento e concessão de bolsista.

\section{Comitê de Ética e Experimentação Animal}

O trabalho foi aprovado pelo Comitê de Ética e Experimentação Animal da Universidade do Estado de Santa Catarina (CETEA/UDESC), Processo no: $1.03 / 05$.

\section{REFERÊNCIAS}

AWAD-MASALMEH, M.; MOON, H.W.; RUNNELS, P.L.; SCHNEIDER, R.A. Pilus Production,

Hemagglutination, and Adhesion by Porcine Strains of Enterotoxigenic Escherichia coli Lacking K88, K99, and 987P Antigens. Infection and Immunity, v.35, n.1, p.305313, 1982.

BACCARO, M.R.; MORENO, A.M.; CORRÊA, A.; FERREIRA, A.J.P.; CALDERARO, F.F. Resistência antimicrobiana de amostras de Escherichia coli isoladas de fezes de leitões com diarréia. Arquivos do Instituto Biológico, São Paulo, v.69, n.2, p.15-18, 2002

BERTSCHINGER, H.U. Escherichia coli Infections. In: STRAW, B.E.; D'ALLAIRE, S.; MENGELING, W.L.; TAYLOR, D.J. (Ed.) Diseases of swine. 8th ed. Ames: Iowa State University Press, 1999. 1181p. p.431-457.

BRITO, B.G.; TAGLIARI, K.C.; BERBEL, M.M.; FREIRE, R.L. Produção de enterotoxina termoestável, hemolisinas, colicina e fatores de colonização em amostras de Escherichia coli isoladas de leitões com diarréia no sudoeste do Paraná. Scientia Agraria, v.4, n.1, p.15-20, 2003.

BURCH, D.G.S. Controlling diarrhoea in growing pigs - the grey scour syndrome. Pig Journal, v.45, p.131-149, 2000.

EVANS, J.R.D.J.; EVANS, D.G.; DUPONT, H.L. Hemagglutination patterns of enterotoxigenic and enteropathogenic Escherichia coli determined with human, bovine, chicken, and guinea pig erythrocytes in the presence and absence of mannose. Infection and Immunity, v.23, n.2, p.336-346, 1979.

FAIRBROTHER, J.M.; LARIVIERE, S.; LALLIER, R. New fimbrial antigen f165 from Escherichia coli serogroup 0115 strains isolated from piglets with diarrhea. Infection and Immunity, v.51, n.1, p.10-15, 1986.

FRANCIS, D.H. Enterotoxigenic Escherichia coli infection in pigs and its diagnosis. Journal of Swine Health and Production, v.10, n.4, p.171-175, 2002a. 
FRANCIS, D.H. Post-weaning Escherichia coli syndrome laboratory perspectives. In: ANNUAL SWINE DISEASE CONFERENCE FOR SWINE PRACTITIONERS, 10., 2002, Iowa, EUA. Proceedings, Iowa, 2002b.

GAASTRA, W.; GRAAF, F.K. Host-specific fimbrial adhesins of noninvasive enterotoxigenic Escherichia coli strains. Infection and Immunity, v.46, n.2, p.129-161, 1982.

GUEDES, R. Avanços na detecção de patógenos entéricos de leitões jovens. In: CONGRESSO LATINOAMERICANO DE SUINOCULTURA, 3, 2006, Foz do Iguaçu, Brasil. Palestras. Foz do Iguaçu, 2006a. p.157-161.

GUEDES, R.M.C.; MACÊDO, N.R.; MENEZES, C.L.P.; LAGE, A.P.; RISTOW, L.E.; REIS-COSTA, A.T. Virulence determinant genes and antimicrobial sensitivity of Escherichia coli strains isolated from diarrheic piglets in the State of Minas Gerais, In: INTERNATIONAL PIG VETERINARY SOCIETY CONGRESS, 19., 2006. Copenhagen, Denmark. Proceedings. Copenhagen, 2006b. 326p.

GYLES, C.L.; PRESCOTT, J.F.; SONGER, J.G.; THOEN, C.O. Pathogenisis of bacterial infections in animals. 3th ed. Iowa: Blackwel, 2004. 456p.

HABRUN, B.; HUMKI, A.; JEMERSIC, L.; CVETNIC, Z.; MITAK, M. Antimicrobial resistence of beta-hemolytic Escherichia coli associated with diarrhea in weaned pigs from large pig breeding farms in croatia. In: CONGRESS OF THE INTERNATIONAL PIG VETERINARY SOCIETY, 18., 2004, Hamburg, Germany. Proceedings. Hamburg, 2004. 522p.

HANSEN, D. Abordagem pratica da Síndrome Diarréica na Maternidade. In: CONGRESSO LATINOAMERICANO DE SUINOCULTURA, 3., 2006, Foz do Iguaçu, Brasil. Palestras. Foz do Iguaçu, 2006. p.167-178.

HOLLAND, R.E. Some Infectious Causes of Diarrhea in Young Farm Animals. Clinical Microbiology Reviews, v.3, n.4, p.345-375, 1990.

JONES, G.W.; RUTTER, J.M. The association of K88 antigen with haemagglutinatinating activity in porcine strains of Escherichia coli. Journal of General Microbiology, n.84, p.135-144, 1974.

KLEIN, C.S.; MARCHIORI, M.; PIFFER, I.A.; KICH, J.D.; GRANZOTTO, G. Comparação entre as técnicas de microhemaglutinação e aglutinação em látex para Identificação de fímbrias em amostras de Escherichia coli In: CONGRESSO BRASILEIRO DE VETERINÁRIOS ESPECIALISTAS EM SUÍNOS, 11., 2003. Goiânia, Brasil. Anais, Goiânia, 2003. 5.p.

LUDWIG, A.; GOEBEL, W. Haemolysins of Escherichia coli. In: SUSSMAN, M. (Ed.). Escherichia coli mechanisms of virulence. Cambridge: Cambridge University Press, 1997. p.281-329.
MARTINS, M.F.; MARTINEZ-ROSSI, N.M.; FERREIRA, A.; BROCCHI, M.; YANO, T.; CASTRO, A.F.P.; SILVEIRA, W.D. Pathogenic characteristics of Escherichia coli strains isolated from newborn piglets with diarrhea in Brazil. Veterinary Microbiology, v.76, n.1, p.51-59, 2000.

MORRIS, J.A. Escherichia coli fimbrial adhesins. Pig News and Information, v.4, n.1, p.19-21, 1983.

NATARO, J.P.; KAPER, J.B. Diarrheagenic Escherichia coli. Clinical Microbiology Reviews, v.11, n.1, p.142-201, 1998.

NATIONAL COMMITTEE FOR CLINICAL LABORATORY STANDARDS. (US). Performance Standards for Antimicrobial Disk Susceptibility Tests. 8 ed. Wayne PA: NCCLS, 2003. 62p. [Aproved standart M2-A8].

OSEK, J. Prevalence of virulence factors of Escherichia coli strains isolated from diarrheic and healthy piglets after weaning. Veterinary Microbiology, v.68, n.3/4, p.209-217, 1999.

POST, K.W.; BOSWORTH, B.T.; KNOTH, J.L. Frequency of virulence factors in Escherichia coli isolated from pigs with postweaning diarrhea and edema disease in North Carolina. Swine Health Production, v.8, n.3, p.119120, 2000.

QUADRI, F.; HAQUE, A.; FARUQUE, S. M.; BETIELHEIM, K.A. ROBINS-BROWNE, R.; ALBERTV, A. Hemagglutination properties of enteroaggregative Escherichia coli. Journal of Clinical Microbiology, v.32, n.2, p.510-514, 1994.

QUINN, P.J.; CARTER, M.E.; MARKEY, B. Clinical veterinary microbiology. London: Wolfe, 1994. 648p.

ROMERO, M.A.; BERNARD, F.; PRONOST, S.O.; FORTIER, G.O.; LOISNARD, D.O.; MONTIER, S.O. Origen bacteriano y parasitário de las diarreas en transición en Francia. Anaporc: Revista de Porcinocultura, v.18, n.180, p.5-29, 1998.

SNYDER, I.S.; KOCH, N.A.; Production and characteristics of hemolysins of Escherichia coli. Journal of Bacteriology, v.91, n.2, p.763-767, 1966.

VAN DEN BOSCH, J.F.; EMÖDY, L.; KÉTYI, I.

Virulence of haemolytic strains of Escherichia coli in various animal models. FEMS Microbiology Letters, v.13, n.4, p.427-430, 1982.

WILSON, M.R.; HOHMANN, A.W. Immunity to Escherichia coli in pigs: Adhesion of enteropathogenic Escherichia coli to isolated intestinal epithelial cells. Infection and Immunity, v.10, n.4. p.776-782, 1974.

Recebido em 13/4/07

Aceito em 19/8/08 